\title{
"We are not Hard to Reach, but we may find it Hard to Trust".... Involving and Engaging 'Seldom Listened to' Community Voices in Clinical Translational Health Research: A Social Innovation Approach.
}

\section{Safina Islam}

The University of Manchester

Olivia Joseph

Bradford Institute for Health Research Yorkshire Quality and Safety Research Group

Atiha Chaudry

Manchester BME Network

Davine Forde

Manchester BME Network

Annie Keane

Manchester University NHS Foundation Trust

Cassia Wilson

Manchester University NHS Foundation Trust

Nasima Begum

Freelance

\section{Suzanne Parsons}

Manchester University NHS Foundation Trust

\section{Tracy Grey}

Manchester University NHS Foundation Trust

\section{Leah Holmes}

Manchester University NHS Foundation Trust

Bella Starling ( $\square$ bella.starling@mft.nhs.uk)

Manchester University NHS Foundation Trust https://orcid.org/0000-0001-9981-5637

\section{Methodology}

Keywords: Diversity, inclusion, BAME, ethnic groups, public involvement, innovation, community engagement, translational research

Posted Date: December 4th, 2020 
DOI: https://doi.org/10.21203/rs.3.rs-117166/v1

License: (c) (1) This work is licensed under a Creative Commons Attribution 4.0 International License. Read Full License 


\section{Abstract}

Background: Public involvement in clinical translational research is increasingly recognized as essential for relevant and robust research. Public involvement must be diverse and inclusive to enable research that has the potential to reach those that stand to benefit from it the most, and thus address issues of health equity. Several recent reports, however, indicate that public involvement is exclusive, including in its interactions with ethnic groups. This paper outlines a novel community-led methodology - a community sandpit - to address the inclusion of ethnic groups in public involvement in research, reports on its evaluation, findings, legacy and impact.

Methods: Through careful planning, relationship-building, co-design and co-delivery between the Public Programmes team based at Manchester University NHS Foundation Trust and the Greater Manchester Black and Minority Ethnic Network, the community sandpit was held in July 2018.

Results: 15 community organisations took part in the participatory 2-day event, as well as 6 researchers, and 6 creative practitioners. 6 community-based partnership projects were seed-funded; 4 of these carried on to receive additional funding.

Conclusions: Evaluation of the sandpit showed the format to be well-received by all: it levelled power relationships between community organisations, health researchers and research infrastructure; it developed capacity amongst researchers about the accessibility, role and potential of community organisations. Described as "not another community seed fund" by community partners, the sandpit offered equitable avenues for collaboration within Greater Manchester translational research and led to the formation of the Black, Asian and Minority Ethnic Research Advisory Group. The method has the potential to be replicated elsewhere to support inclusive public involvement in research and inclusive research.

\section{Plain English Summary}

Public involvement in "bench to bedside" research is increasingly recognized as essential for relevant and robust research. To enable research to reach those that stand to benefit from it the most, and thus address issues of health equity, public involvement must be diverse and inclusive. Several recent reports, however, indicate that public involvement is exclusive, including in its interactions with ethnic groups. This paper outlines a novel community-led methodology - a community sandpit - to address the inclusion of ethnic groups in public involvement in research, reports on its evaluation, findings, legacy and impact.

Through careful planning, relationship-building, co-design and co-delivery between the Public Programmes team (now Vocal) based at Manchester University NHS Foundation Trust and the Greater Manchester Black and Minority Ethnic Network, the community sandpit was held in July 2018. 15 community organisations took part in the participatory 2-day event, as well as 6 researchers, and 6 creative practitioners. 6 community-based partnership projects were seed-funded; 4 of these carried on to 
receive additional funding. Evaluation of the sandpit showed the format to be well-received by all: it levelled power relationships between community organisations, health researchers and research infrastructure; it developed capacity amongst researchers about the accessibility, role and potential of community organisations. Described as "not another community seed fund" by community partners, the sandpit offered equitable avenues for collaboration within Greater Manchester translational research and led to the formation of the Black, Asian and Minority Ethnic Research Advisory Group. The method has the potential to be replicated elsewhere to support inclusive public involvement in research and inclusive research.

\section{Background}

\section{Diversity in public involvement in health research in the UK}

Public involvement in health research is an increasingly accepted component of ethical and relevant health research in England, including through its main funder of health research: the National Institute of Health Research (NIHR) [1]. A strategic review of public involvement in England, however, highlights the need for public involvement to become more diverse and inclusive:

"A diverse and inclusive public involvement community is essential if research is relevant to population needs and provides better health outcomes for all. We have been struck by the degree to which researchers and public contributors have encountered barriers when trying to work with different communities and populations." [2]

More recently a survey of public contributors to NIHR research highlights that the majority of public contributors to NIHR research are older (62\% are between 50 and 79 years old), female (58\%) and White British (77\%) [3]. Young people and minority ethnic communities are under-represented in NIHR public involvement. Only $2 \%$ of public contributors surveyed by NIHR in $2018-2019$ are under $252 \% ; 14 \%$ are aged 26-49. Asian ethnic groups represent only $3 \%$, Black ethnic groups only $2 \%$ of NIHR public contributors. Research carried out by the Health Research Authority shows that people from ethnic and lower socioeconomic groups feel far less confident about being treated with dignity and respect in research compared to their White and higher socioeconomic counterparts (35\% of ethnic minority respondents feel confident compared to $50 \%$ of White respondents) [4]. Likewise, in the neighbouring field of science communication, informal science education has been 'exclusive', and many audiences are 'underserved' by science communication (cf. British Science Association audience map) [5, 6].

\section{Barriers to inclusion of ethnic communities in research}

A growing evidence base explores reasons for the low levels of public involvement of ethnic groups, including Black, Asian and Minority Ethnic (so-called "BAME") groups in clinical and translational health research [7]. Analyses of research participation in clinical cancer trials, mainly from the US $[8,9,10]$ with some from the UK $[11,12]$ and trials related to other conditions such as asthma [13] and mental health [14] in South Asian and African-Caribbean communities in the UK and abroad, provide complementary 
evidence for barriers to involvement. Strategies to reduce inequalities in healthcare have identified the representation of diverse groups in clinical research as an important component of research studies [15, $16]$.

We acknowledge the differences and complementarities between participation, engagement and involvement in health research [17]. Based on some of the existing literature (above) and our collective experience of engaging and involving diverse audiences with scientific research since 2003 , barriers to inclusion of diverse communities in health research can cut across participation, engagement and involvement and are summarized in Table 1. 
Barriers related to participation, engagement and involvement of ethnic groups in health research

\section{Barriers related to research culture}

Increased cost The perception that the addition of extra variables such as ethnic diversity of of studies participants would increase the cost and duration of research studies, through the requirement of more sub-group analyses and increased recruitment costs

Attitudinal barriers

Language, communication and cultural barriers

Lack of awareness

Study design
Researchers (along with the rest of society) may have unconscious bias or preconceptions about whether patients from certain groups are interested in participating in a study or not due to stereotypes or cultural myths.

Often there is no guidance or resources for researchers to address the inclusion in research studies of patients where English is not a first language, so such patients are automatically excluded from a study. Ethics committee requirements to translate all written material in different languages can have little positive impact when many community languages are not generally used in a written form, or low levels of health literacy are not accounted for in the material.

The historical and conceptual understanding of race, ethnicity and culture can make the recruitment of people from ethnic minority backgrounds appear more problematic to researchers

Case selection biases that tend to structurally exclude BAME patients and individuals with lower socioeconomic status, as they tend to have poorer health in general. Overly complex information containing jargon and consent forms can exclude potential participants from different backgrounds even when command of English is good.

\section{Barriers related to healthcare}

Structural

health

inequalities

and racism
So-called 'underserved' populations can expect higher incidence rates of conditions (eg. Cancer) because of structural exclusion and unmet need (eg. Inadequate access to prevention and screening, later diagnosis, exclusion criteria/recruitment bias in research studies) or and/or unmet need through exclusive research priorities and design.

Power dynamics
Power dynamics inherent in social and health inequalities acknowledge that the structure and models for involvement (e.g. use of meeting rooms, rigid agendas, chairing of meetings) can be exclusive or culturally imperialist. Is this conducive to the development of trust, valued involvement and creation of equal knowledge spaces? $[18,19,20]$

\section{Barriers related to society and heritage}

Mistrust of anchor institutions and/or healthcare providers
Often cited as the most common barrier to the participation of ethnic groups in clinical trials. Poor previous experiences and low satisfaction in a healthcare or other institutional (eg. Higher Education, justice) setting can often lead to patients not wanting to participate in a study. Distrust around sharing or misuse of personal information and data protection issues is also higher in ethnic groups [cf. 4]

\section{Barriers within communities}

Lack of understanding of the research process
In disadvantaged and marginalised communities, this can lead to a rejection to an invitation to participate. Roles for patient advocates and navigators could support the recruitment and retention in the early stages of a trial to ensure retention of patients from 'underserved' communities. 


\section{Barriers related to research culture}

Socioeconomic Decisions by patients to participate may be driven in part by socio-economic status status. Loss of income (actual or perceived) or costs incurred by participation, engagement and/or involvement in research (due to increased hospital visits, for example) may deter participation.

Flexibility

Lack of flexibility around timing can prevent many patients and carers or participation, engagement and/or involvement. Common reasons include childcare, carer responsibilities and employment in sectors that wouldn't approve extra time off to attend participation or involvement activities.

Stigma Different cultural/faith of patients can impact their perceptions of health, research and participation in a clinical trial.

\section{Working with seldom listened to communities in a social innovation approach}

Some helpful guides to working with ethnic individuals, groups and communities in research already exist $[21,22,23,24]$ and have been published during the preparation of this paper [eg. 25]. To address greater inclusion, and explore some of the deeper barriers to engagement and involvement in health research, beyond tokenism or a temporary solution, we piloted a new approach - a community sandpit - based on principles and practices of social innovation and co-production [26].

Sandpits are intensively facilitated workshops which aim to uncover innovative solutions. They bring together a mix of people, give them time to talk and exchange ideas, and then fund the projects that they are able to come up with. We chose this model to encourage community-led innovation in public involvement because it allows different sectors to recognise the knowledge and expertise that they can bring and provides a safe space to experiment and to find new collective solutions. The model also aims to be fun and engaging, and use creative activities and tools which enable new dialogue and ideas to emerge.

We have previously reported on our strategic approach to working across public engagement and involvement, $[17,27]$ which includes a focus on diversifying the audiences and producers of public involvement and effecting a shift from 'research led' engagement, involvement and research to 'community-led' engagement, involvement and research. Here we report on the methodology and impact of the sandpit, and suggest it as a replicable way to work with communities in public engagement and involvement to ultimately foster inclusive research. We also report on the legacy of the sandpit: the establishment of a Black, Asian, Minority Ethnic Research Advisory Group (BRAG).

\section{Methods}

In July 2018, a two day community sandpit event brought together over 30 Voluntary and Community Sector (VCS) organisation representatives, creative practitioners, community leaders, researchers and 
public involvement practitioners from across Greater Manchester (GM, Fig. 1, event flyer).

\section{Aims and principles}

The aims for the sandpit were to:

- Build meaningful relationships with diverse community organisations and health research

- Administer a community seed fund to explore community led innovation in the sector

- Level the playing field between community organisations and researcher anchor institutions

- To bring researchers, community organisations and artists together to collaborate and explore solutions for the lack of diversity of people involved/participating in health research

At the outset, we elaborated some key principles to apply to the sandpit. We:

- Emphasised a co-design approach when working with community partners

- Valued community organisations as experts rather than gate keepers or community leaders

- Put health research in contexts that have a practical interest to community groups and their users

- Used creative approaches to trigger discussion and debate and create a learning together environment

- Valued the time and expertise of community organisations

- Used methods to level the playing field between different types of community organisations

\section{What we did}

\section{Sandpit partner}

Through existing voluntary and community sector (VCS) contacts, the Public Programmes Team (now Vocal) [28] initially mooted the idea of a sandpit, and then sought active and equitable partnership with the GM Black and Minority Ethnic Network (GMBME) [29] to develop the idea further, then co-design and promote the Community Sandpit event. The GMBME has extensive knowledge of the VCS sector, wide reach amongst grassroots community organisations, as well as having supported different health promotion and infrastructure development initiatives across Greater Manchester.

\section{Relationship development, co-design, promotion and recruitment}

Active involvement in health research was a new area of focus for many of the community organisations who would eventually take part in the sandpit. Working with ethnic and community groups was also a new area for many of the researchers taking part. A significant amount of time was spent developing relationships both with researchers and with GMBME members and community organisations, to give background to the initiative, answer questions and secure buy-in. As an established community organizer 
and leader, the first author of this paper was already a trusted individual within community and ethnic groups in GM. The Public Programmes team is a trusted partner for researchers in GM.

Working in partnership between the Public Programmes Team and the GMBME Network, the event was designed to ensure that organisations that put forward staff or volunteers to participate did not have to resource staff time to attend. Staff/volunteer time was valued at the rate NIHR INVOLVE recommends for patient contributors and payment was made to organisations or individuals as appropriate.

Both days were designed with time built in to focus on community organisations/artists learning about public involvement and health research. The GMBME network used its existing communication channels that included the web presence of its parent organization, GMCVO, one of the largest VCS infrastructure support organisations in the GM conurbation, its own email newsletter mailing list and network events and meetings leading up to the registration deadline for the event to promote and recruit staff. A promotional flyer was also produced (Box 1)

\section{Sandpit event}

The community sandpit events were delivered over 2 days with a one day break in between to allow participants time to process what they had learnt and think about the second day.

Day 1 consisted of facilitated activities to enable representatives from community organisations/artists to familiarise themselves with public involvement and health research in the GM context, including the activities of the Public Programmes Team, the NIHR Manchester Biomedical Research Centre (MBRC), the NIHR Manchester Clinical Research Facility (MCRF) and the NIHR GM Patient Safety Translational Research Centre (GM PSTRC). The first day was highly interactive day with lots of opportunity for discussion and debate, including activities designed to address different power dynamics in the room. The activities included "the unseen" (a creative activity that enabled the participants to really consider the process of discovery and their own reflexivity in developing research questions) and some role play where the participants experienced a mini-patient research panel with some actual research examples.

On day 2, researchers joined the discussions, there were presentations relating to health conditions and prevalence in diverse communities, following some speed networking where researchers and artists presented what specific skills they could add to any projects that were going to be pitched. The participants then, worked in small groups to devise a new project/event that would and engage their communities in health research, with a view to developing a research question and/or project of relevance to communities. Each project was pitched to the whole audience and after an interactive audience voting process and the winning projects were awarded funding (of between $£ 500-£ 750$ ) at the end of the day.

\section{Evaluation}

\section{Evaluation against Sandpit aims}


At the end of the Sandpit, a simple questionnaire with 10 questions captured of a mixture of quantitative and qualitative indicators against the Sandpit aims. This included a Likert scale indicating how well the participants felt the activities went, whether they able to contribute and whether they felt listened to, and space for some free text responses.

Following the sandpit, one to one interviews with a sample of 5 participants within 4 weeks of the event and a focus group of 12 of the participants within 16 weeks of the events as well as reflections and observations recorded by the facilitators and practitioners supporting the event. All the data was collated and a simple matrix thematic analysis conducted to elucidate common themes.

\section{Follow up}

Where required, staff from the GMBME Network and/or the Public Programmes Team supported the community organisations that won pitches to deliver their projects and record/observe their community reach. This happened through project delivery, supporting or refining the scope of the project, and its evaluation. An informal feedback and sharing event was held in Feb 2019 where community organisations that were funded were invited to share the outputs and any learning from their projects with the whole group.

\section{Results}

\section{Summary of the Sandpit}


Table 2

Community Sandpit at a glance

\section{Expressions of interest from community organizations}

Number of community organisations selected to participate

Number of creative practitioners taking part

Number of researchers taking part

Ideas for projects

Pitches funded

Projects subsequently receiving additional funding
30

15, selected by the Public Programmes team and GMBME, to ensure a broad representation of different communities of interest, geographical spread across $\mathrm{GM}$ and experience of working on health issues

\section{Funded projects}

The following projects won pitch funding and were delivered between September 2018 and January 2019 (Table 3) 
Table 3

Community-led research and engagement projects funded through the Community Sandpit

\begin{tabular}{|c|c|c|}
\hline Skin deep & $\begin{array}{l}\text { Focused on skin problems and treatments in the African community } \\
\text { in South Manchester, the project aims to engage up to } 50 \text { parents } \\
\text { and children, and to help researchers identify key research priority } \\
\text { for African skin health. }\end{array}$ & $\begin{array}{l}\text { AfroTots and } \\
\text { researchers in } \\
\text { the } \\
\text { Manchester } \\
\text { BRC } \\
\text { Dermatology } \\
\text { theme }\end{array}$ \\
\hline $\begin{array}{l}\text { Shisha or } \\
\text { no shisha }\end{array}$ & $\begin{array}{l}\text { An action research project capturing responses from people who } \\
\text { frequently visit Wilmslow Road area where most of the City's Shisha } \\
\text { Cafes operate. A 5-10 minute film of the project will indirectly } \\
\text { raising awareness about the effects of shisha smoking and } \\
\text { stimulate insights into people's attitudes towards Shisha smoking. }\end{array}$ & $\begin{array}{l}\text { A partnership } \\
\text { between the } \\
\text { Ethnic Health } \\
\text { Forum, } \\
\text { C4Change, } \\
\text { GMBME } \\
\text { Network, } \\
\text { University of } \\
\text { Manchester } \\
\text { and the } \\
\text { Public Health } \\
\text { Team at } \\
\text { Manchester } \\
\text { City Council }\end{array}$ \\
\hline $\begin{array}{l}\text { Amplifying } \\
\text { Voices }\end{array}$ & $\begin{array}{l}\text { A training toolkit to enable authentic ethnic voices to be amplified } \\
\text { within health research, across } \mathrm{GM} \text {, to support research to become } \\
\text { more culturally appropriate and influence health outcomes. }\end{array}$ & $\begin{array}{l}\text { A partnership } \\
\text { with Afro } \\
\text { Tots, } \\
\text { Dynamic } \\
\text { Support, CS- } \\
\text { UK, the New } \\
\text { Testament } \\
\text { Church, } \\
\text { Alchemy Arts, } \\
\text { Ethnic Health } \\
\text { Forum, } \\
\text { Wonderfully } \\
\text { Made } \\
\text { Woman, and } \\
\text { Big People's } \\
\text { Music. }\end{array}$ \\
\hline $\begin{array}{l}\text { Speak out } \\
\text { your voice is } \\
\text { your power }\end{array}$ & $\begin{array}{l}\text { A community leaders engagement workshop for Black Nigerian } \\
\text { women during Black History Month in Central and East Manchester } \\
\text { focused on domestic violence. The project aims to support } \\
\text { researchers to understand how some isolated and vulnerable } \\
\text { women can be reached and engaged in research on domestic } \\
\text { violence. }\end{array}$ & $\begin{array}{l}\text { Wonderfully } \\
\text { Made Woman }\end{array}$ \\
\hline
\end{tabular}




\begin{tabular}{|c|c|c|}
\hline Skin deep & $\begin{array}{l}\text { Focused on skin problems and treatments in the African community } \\
\text { in South Manchester, the project aims to engage up to } 50 \text { parents } \\
\text { and children, and to help researchers identify key research priority } \\
\text { for African skin health. }\end{array}$ & $\begin{array}{l}\text { AfroTots and } \\
\text { researchers in } \\
\text { the } \\
\text { Manchester } \\
\text { BRC } \\
\text { Dermatology } \\
\text { theme }\end{array}$ \\
\hline $\begin{array}{l}\text { Menopause } \\
\text { monologues }\end{array}$ & $\begin{array}{l}\text { the project will be a platform and provide opportunities for up to } 20 \\
\text { South Asian women to talk about their experiences and tell stories } \\
\text { about menopause - a taboo and sensitive subject in some South } \\
\text { Asian cultures. Stories will be recorded to engage further audiences } \\
\text { in a peer-to-peer approach. The project aims to empower women to } \\
\text { take an active role in health and research related to the menopause; } \\
\text { to stimulate research into South Asian women's experiences of } \\
\text { menopause; help shape health care services for women regarding } \\
\text { menopause; to break down barriers to engagement; promote access } \\
\text { to services for South Asian women around menopause; breakdown } \\
\text { menopause myths, stigma and taboo }\end{array}$ & $\begin{array}{l}\text { Community } \\
\text { artist }\end{array}$ \\
\hline $\begin{array}{l}\text { Leading } \\
\text { through } \\
\text { lived } \\
\text { experience } \\
\text { for positive } \\
\text { change }\end{array}$ & $\begin{array}{l}\text { The project will investigate and document up to } 6 \text { lived experience } \\
\text { leaders who have set up projects for positive change and health } \\
\text { outcomes. The project aims to share good practice of how lived } \\
\text { experience leaders have set up initiatives and projects to improve } \\
\text { health and well-being outcomes for people who access their project } \\
\text { or initiatives and to learn how the lived experience leaders expertise } \\
\text { can be utilised to support community engagement with research }\end{array}$ & $\begin{array}{l}\text { Shining Stars } \\
\text { community } \\
\text { group }\end{array}$ \\
\hline
\end{tabular}

\section{Sandpit format}

The format of the sandpit was felt to be engaging and relevant:

"Very clear and transparent event" (Participant 8)

"I hope we will get to do another session. It was an eye opener." (Participant 9)

"It was fun and relaxed but with a really focused and important message" (Participant 14)

Of the 16 people who responded, $75 \%$ felt they were adequately prepared for the event, answering ' $N \mathrm{No}^{\text {' to }}$ the question: Was there anything else you would have liked to have known before coming to the Sandpit? A few expressed suggestions for improvement - they would want to have:

"a better/clear understanding of the project overall, i.e. purpose of pitch on day 2" (Participant 3)

"a programme of the day's activities, or some case studies of projects that have come out of previous sandpits so I knew a bit more about the process before attending"(Participant 11)

The activities were felt to be 'interesting' by between $81.25 \%$ and $93.75 \%$ of those responding, depending on the activity. $80 \%$ found the speed meeting a good way of networking. 
$95 \%$ of respondents $(n=20)$ found the pitch process 'fun and engaging'. The voting process was found to be a good way of choosing winning projects quickly, by $80 \%$ of respondents $(n=20)$ and $90 \%$ felt able to contribute to choosing winners. Two community groups decided not to pitch and some reservations were expressed: some participants felt that the funding pots were not enough to scope or pilot a meaningful project and some felt they needed additional time to develop a pitch. Four of the community participants felt strongly that only community partners should have a vote.

"It did feel that those who knew each other voted for each other" (Participant 3)

\section{Was the Sandpit inclusive? Did it 'level the playing field'?}

Attendees found the event inclusive:

- $100 \%$ felt that their 'views were valued (after Day 1)'

- $100 \%$ felt that 'the sandpit a good way of getting people to work together (after day 2)'

- $95 \%$ felt able to contribute

Participants - community organisations, artists, researchers and facilitators - felt that the event had addressed power dynamics between researchers and communities, enabling a 'safe space' and more level 'playing field':

"First-time in a long time a piece of real collaborative work was done, where we felt really valued" (Facilitator 1)

"We talk about collaboration and partnership working but it doesn't actually happen. This event put community organisations on an equal footing and values their time and input, even between community organisations" (Facilitator 2)

"It worked really well and allowed people with a safe space to work together" (Participant 4)

Everything worked really well. The researchers were amazing and willing to be challenged (Participant 13)

People learned about each other and about the work of their organisations

"I learnt so much about the many diverse activities and the work of the organisations that support them" (Participant 14)

"It was a day for me to learn something that I didn't know before. It has increased my knowledge about health research." (Participant 6)

\section{Addressing inclusion in health research and involvement}

Much of the discussion and dialogue throughout the two days focused on the lack of diverse voices being involved in health research. There were different levels of understanding as to the impact of this at 
the beginning. By the end of the two days increased awareness of this issue evolved, and a call to action for health research and involvement to work more in partnership with community organisations, including with community artists emerged.

"Yes - a really brilliant first step in getting researchers, NHS, Academics talking to artists for the betterment of our community and to have these community voices heard." (Participant 5)

"I thought it was an excellent opportunity for us to get together to find out more about each other and to network and plan projects together." (Participant 3 )

"It was a brilliant way of getting to know and working with others that I do not usually get to work with or did not know prior to this event." (Participant 13)

Some participants talked about the rhetoric and language around so-called 'hard to reach groups' in health research and involvement:

We are not that hard to reach, but we might find it hard to trust you...

(Facilitator 1)

As a researcher, really opened my eyes to the fact that engaging communities wasn't that hard. We are told almost from the start as students that they are hard to reach.

(Participant 17)

\section{Reflections from researchers}

Overall, researchers found the day valuable and it challenged some of their conceptions of community engagement and public involvement in research:

"Maybe there should be 'how to involve researchers in communities' rather than involving communities in research?" (Participant 2)

The majority of researchers were happy to work with community participants as part of the Sandpit, to develop their ideas and design projects around health research and involvement. A minority (one researcher) would have preferred the Sandpit participants to focus on specific ways to engage communities in their existing research projects and that researchers should have attended both days.

"Not much link to research. Few/no pitches mentioned involving researchers - mostly about health promotion. Attendance and contribution from more researchers and more senior researchers" (Participant 2)

\section{Unexpected outcomes}

As well as following through the funded projects, the legacy of the Sandpit includes: 
- The GMBME network as an established 'go-to' partner of the Public Programmes Team. We continue to partner up on projects as appropriate and to mutually signpost to issues of common interest.

- The establishment of a BAME Research Advisory Group (BRAG) as part of the Public Programmes Team and the MBRC and MCRF.

- Three community organisations are now directly involved with BRC led-health research projects/project scoping by providing expertise and community knowledge

- One community participant from the Sandpit has now joined an internal BRC and CRF strategic group addressing health inequalities in its work, as a public contributor.

\section{Discussion: What Did We Learn?}

\section{How did we do against our aims?}

Overall, we feel that we successfully addressed our aims of:

- Building meaningful relationships with diverse community organisations and health research

- Levelling the playing field between community organisations and researcher anchor institutions

- Administering a community seed fund to explore community led innovation in the sector

- Bringing researchers, community organisations and artists together to collaborate and explore solutions for the lack of diversity of people involved/participating in health research

\section{Format of the Sandpit}

The results of our evaluation show that the Sandpit format was accessible, engaging and inclusive for all involved. Getting 'hands-on' including through creative activities and, for example, mock 'patient panel' exercises really helped to bring to life both the Sandpit environment and the reality of what public involvement can 'look like'. In line with our published approach [17] creative approaches triggered discussion and debate which led to rich and meaningful dialogue. Having presentations about health and research contexts related to $\mathrm{GM}$ and to the community organizations present, also helped to make the context of the Sandpit relevant. Making content relevant to the audience supported more long term thinking about what needs to happen in the sector and how participants could have a role in its transformation.

It was important for us to create a 'safe space' at the beginning of the Sandpit. The event was purposefully located (in a netural space in central library), designed and promoted without much information about the format and content, in order to enable everyone to start the same 'place'. Whilst this approach was welcomed by the majority of the participants, some participants were uncomfortable about not knowing what was expected of them and would have liked much more time to prepare. Overall, however, our evaluation shows that the Sandpit format enabled a safe, respectful and equal exchange of ideas and skills. 
To subvert some of the usual power relationships $[18,19,20]$ in public involvement in health research, Day 1 of the Sandpit did not include researchers, in order to provide background, context and help create the 'safe space'. A minority of researchers questioned this approach; however, in the preparation of the Sandpit, when researchers were canvassed about attending an event, many would have been unable to come away from the demands of their research schedule for two full days. This is relevant to a wider discussion about how much time and value research culture accords to public involvement (see also below).

Overall, the 'pitching' process was successful. Two community groups decided not to pitch, some participants felt that the funding pots were not enough to scope or pilot a meaningful project and some felt they needed additional time to develop a pitch. Whilst we had co-designed what we thought was a fair voting process, at least four of the community participants felt strongly that researchers and/or members of the Public Programmes Team should not have a vote and that, potentially, different projects would have been funded if only community participants had a vote and this would give an indication of what matters more to communities regarding health research. This is something to bear in mind for future Sandpit design.

We learned to be prepared for unexpected interpretations of the pitch 'brief'. Although time was allowed in the Sandpit design for participants to think about the pitch brief (in this case - designing a project that would encourage their service users/communities to get involved in health research) a few pitched projects focused more on more traditional health promotion. Whilst this could be considered a 'failure' of the process, it enabled further group exploration of the health issues at hand, and their relation to research. Taking the time to engage with these 'health promotion' pitches also allowed further trust and dialogue to be established with community partners.

\section{Co-design/Partnership process}

We invested time to try and ensure all partners felt that they were equal in the development of the project whilst working with a clear understanding of our roles and responsibilities around delivery. The time needed to develop trust and build relationships with community partners needs to be factored in to the development phase of a co-designed project of this nature [22]. A positive partnership was created between the main partners (the Public Programmes Team and the GMBME Network) which was then extended to the community groups that make up the network and the researchers associated with the Public Programmes Team. This resulted in a much higher than expected response from groups wanting to participate in the sandpit event.

Additional benefits of working with a network as a community partner included being able to use existing communications channels, having access to local intelligence about what health topics were already an issue in different communities and what other initiatives were currently happening in different geographical areas that would prevent (or incentivize) certain groups from engaging with this project.

\section{Conscious, asset-based community engagement}


Our starting point was to focus on building relationships with community organisations as experts in reaching their communities, having existing trust and relationships with individuals who attend their centres and groups. Using this asset-based approach was valuable. Rather than seeing community organisations as 'gatekeepers' or conduits to reach individuals or service users in their communities, trust was established by valuing the assets of community organisations in their own right. Creative practitioners were similarly valued in the context of the increasing evidence that arts-based approaches can positively address social and health issues [30,31].

We tried not to use a traditional 'seed funding' processes where community organisations are required to invest energy and resources to compete for a small amount of funding (that they might not get). Even when successful, traditional seed funding does not always cover the costs of upfront investment let alone project delivery. Therefore our approach was designed to value their time and expertise. Community participants was valued through payment to their organisations in line with NIHR INVOLVE guidance and in the time spent by the project team before the event and after the event liaising with project partners and funded projects. Participants from smaller grassroots organisations reported that they felt they were better placed to interact with the larger voluntary sector organisations (who were normally better placed to access small pots of funding because they have often have access to additional resources, such as a fundraising officer) as all the pitching and voting was done within the 2 days of the community sandpit.

\section{Addressing inclusion in public involvement in health research}

The funded projects all addressed issues of diversity and inclusion in health research. They have reached deeper into communities to engage and involve diverse audience with health research. At least one of the funded projects has also led to a grant application for research, with the community partner as a coapplicant. Several of the other projects have gone on to receive further funding. All have increased the capacity and capabilities of community organisations to take an active role as partners in both health research and public engagement with health research.

Projects that were funded were also on the whole quite ambitious and this required some support to get them on track and feasible within the time and resources. If the Sandpit is repeated, adequate resources need to be built in to support project delivery and evaluation.

Participants valued the time getting to know each other's 'worlds'. Researchers appreciated understanding more about community organisations (including community artists), how they work, and who they work with; community organizations felt able to understand more about research and research culture. Of particular interest, the comments made about the language of 'hard to reach' revealed conflicting perspectives, but ones which might have become closer through the Sandpit activities:

We are not that hard to reach, but we might find it hard to trust you...

As a researcher, really opened my eyes to the fact that engaging communities wasn't that hard. We are told almost from the start as students that they are hard to reach. 
The sandpit was felt to 'open researchers' eyes' about working with ethnic communities partnering and valuing community organsations. It highlighted the diversity of community organisations to researchers, how grassroots organisations work and the intricacies of their relationships both within communities and with health and research providers. In addition, some of the comments from researchers reveal the prevailing research culture as viewing public involvement as an intervention rather than a relationship. For example, the expressed desire for the Sandpit to focus on engagement with existing research projects focuses on a transactional, instrumental view of public involvement rather than a research culture that values the time taken to establish trust between partners.

The unexpected outcomes of the Sandpit, notably the establishment of the BRAG and the membership of the Manchester BRC and CRF Health Inequalities Steering Group [32], have the potential to strategically influence research culture to ensure more inclusive practices.

From the evaluation of the community sandpit, there was enthusiasm and energy to continue to foster an engaged relationship between community organisations and health research. Eight community connectors expressed an interest and two meetings were held to discuss the purpose, scope and logistics of the group. The Black Asian and Minority Ethnic Research Advisory Group (BRAG) was established in January 2019 in partnership with the Public Programmes Team.

The group is community led with an emphasis on generating solutions and not being hamstrung into traditional formats of involvement. Funded through an award made from the Wellcome Trust to the Public Programmes team, BRAG's remit is to provide expertise and advice on inclusive practices; to involve diverse audiences in the development, delivery and dissemination of health research. This responds to the strategic priorities of the Public Programmes Team, operating across GM health research infrastructure (including the MBRC and the MCRF) of developing 'community-led' priorities, projects and approaches. To date (winter 2020), BRAG have

- Advised on 5 research projects in 2019-2020

- Advised on public engagement and communications projects, including the rebrand of the Public Programmes team (to Vocal) to support greater reach within communities

- Developed Top Tips for Researchers who wish to work with BRAG

- Co-authored blogs, with academics and members of the Public Programmes team [eg. 33]

- Co-presented at national events eg. Equality and Diversity in Science Symposium 2019

- Co-designed and co-delivered (with Public Programmes) training on Inclusive Research for GM-based health researchers.

- Engaged audiences through creative means

- Received leadership training, with a focus on involvement in health research

- Received training on health research processes and structure within GM

- Acted as co-applicants on several funding bids to NIHR and others 
- Begun to form strategic research partnerships with GM research infrastructure (eg. Manchester Cancer Research Centre)

\section{Conclusion}

Overall the community sandpit event was a good starting point to engage grass roots community organisations with public involvement and health research. It raised awareness of the different ways in which communities can be engaged and provided practical learning on how to 'level the playing field' between community and research organisations, while at the same timeenabling community representatives to network and also speak face to face with researchers. The event enabled relationships to be formed and trust to be built so that more long term engagement and involvement can then take place. Recognising community assets, expertise and innovation (often with minimal resource) can provide a change for academic institutions to learn how to access wider audiences and provide further opportunities for partnerships across different sectors.

The sandpit addressed many of the concerns and challenged outlined in the introduction to this paper, in particular demonstrating how dignity and respect can be addressed through a community-led, assetbased and partnership approach. The sandpit has further demonstrated impact through its legacy in BRAG and chimes with recent research culture initiatives emphasizing the need for greater race equality and inclusion in research (eg. The INCLUDE project, and the establishment of an NIHR Race Equality Panel).

\section{Declarations}

\section{Ethics approval and consent to participate:}

Not applicable

\section{Consent for publication:}

Not applicable

\section{Availability of data and materials:}

Data sharing is not applicable to this article as no datasets were generated or analysed during the current study.

\section{Competing interests:}

The authors declare that they have no competing interests 


\section{Funding:}

This work was funded by the NIHR Manchester Biomedical Research Centre, the NIHR Manchester Clinical Research Facility and the Wellcome Trust. The views expressed are those of the author(s) and not necessarily those of the NHS, the NIHR, the Department of Health or the Wellcome Trust.

\section{Authors' contributions:}

SI led the community sandpit described in this paper, from the initial idea to partnership, implementation and evaluation.

$\mathrm{OJ}, \mathrm{AK}, \mathrm{CW}, \mathrm{LH}, \mathrm{SP}$ and BS supported the sandpit delivery and evaluation through strategic and operational oversight and support.

SP supported the project's evaluation.

AC represented the GM BME network as a co-producer of the work outlined in this manuscript. DF represented the Manchester BME CIC and is a public contributor to the Health Inequalities Steering Group. NB contributed as a creative practitioner involved in the sandpit. AC, DF and NB contributed to the sandpit, and its evaluation analysis.

TG and AK are the facilitators for BRAG and contributed to manuscript sections related to BRAG.

$\mathrm{SI}, \mathrm{OJ}$ and BS were major contributors in writing the manuscript. BS and LH are both corresponding authors. All authors read and approved the final manuscript.

\section{Acknowledgements}

The authors acknowledge all the community organisations and researchers involved in the community sandpit described in this publication.

\section{References}

1. National Institute of Health Research https://www.nihr.ac.uk/ (accessed 16 November 2020)

2. Going the Extra Mile https://www.nihr.ac.uk/patients-and-public/documents/Going-the-Extra-Mile.pdf (accessed 16 November 2020)

3. Taking Stock - NIHR public involvement and engagement https://www.nihr.ac.uk/documents/taking-stock-nihr-public-involvement-andengagement/20566\#NIHR_public_contributors\%E2\%80\%99_feedback_survey (accessed 16 November 2020). 
4. Health Research Authority. Survey of the general public: attitudes towards health research 2017. https://www.hra.nhs.uk/about-us/news-updates/survey-finds-strong-public-support-health-research/ (accessed 16 November 2020)

5. British Science Association Audience Model https://www.britishscienceassociation.org/ouraudience-model (accessed 16 November 2020)

6. Dawson, E. Equity in informal science education: developing an access and equity framework for science museums and science centres. Studies in Science Education, 2014;50:209-247, DOI: 10.1080/03057267.2014.957558.

7. Dawson S, Campbell SM, Giles SJ, Morris RL, Cheraghi-Sohi S. Black and minority ethnic group involvement in health and social care research: A systematic review. Health Expect. 2018;21:3-22

8. Murthy VH, Krumholz HM, Gross CP. Participation in Cancer Clinical Trials: Race, Sex and Age based disparities. JAMA 2004;291:2720-6 3

9. Symonds RP, Lord K, Mitchell AJ, Raghavan D. Recruitment of ethnic minorities into cancer clinical trials: experience from the front lines. British Journal of Cancer 2012;107:1017-1021

10. Chen MS. Renewing the Case for Enhancing Minority Participation in Cancer Clinical Trials. Cancer 2014;1091-1095

11. Godden S, Ambler G, Pollock AM. Recruitment of minority ethnic groups into clinical cancer research trials to assess adherence to the principles of the Department of Health research governance framework: national sources of data and general issues arising from a study of one hospital trust in England. J Med Ethics 2010;36:358-362

12. Lord K, Ibrahim K, Kumar S, Rudd N, Symonds P. Measuring Trust in healthcare professionals - a study of ethnically diverse UK Cancer patients. Clin Oncol 2011;24:4-12.

13. Rooney LK, Bhopal R, Halani L, Levy M, Partridge MR, Netuveli G, Car J, Griffiths C, Atkinson J, Lindsay G, Sheikh A. Promoting recruitment of Minority Ethnic groups into research: qualitative study exploring the views of South Asian people with Asthma. Journal of Public Health 2011;33:604-615

14. Dawn Edge \& Sara C. MacKian. Ethnicity and mental health encounters in primary care: help-seeking and help-giving for perinatal depression among Black Caribbean women in the UK. Ethnicity \& Health, 2010;15:93-111,

15. Hussain-Gambles $M$, Atkin $K$, Leese $B$. Why ethnic minority groups are under-represented in clinical trials: a review of the literature. Health and Social Care in the Community 2004;12:383-388

16. Fair Society, Healthy Lives: The Marmot Review. 2010

17. Holmes L, Cresswell K, Williams S, Parsons S, Keane A, Wilson C, Islam S, Joseph O, Miah J, Robinson E \& Starling B. Innovating public engagement and patient involvement through strategic collaboration and practice. Res Involv Engagem 2019;5:30 https://doi.org/10.1186/s40900-0190160-4

18. Green G. Power to the people: To what extent has public involvement in applied health research achieved this?. Res Involv Engagem 2016;2:28 https://doi.org/10.1186/s40900-016-0042-y 
19. Locock L, Boylan A-M, Snow R, Staniszewska S. The power of symbolic capital in patient and public involvement in health research. Health Expectations 2017;20:836-844 https://doi.org/10.1111/hex.12519

20. Patient powered research? Starling, B https://www.nesta.org.uk/blog/patient-powered-research/ (accessed 16 November 2020).

21. Toolkit to increase BAME participation in health and social care research https://www.rdseastmidlands.nihr.ac.uk/bame-toolkit-toolkit-to-increase-participation-in-health-and-social-careresearch (accessed 16 November 2020).

22. NIHR INVOLVE https://www.invo.org.uk/current-work/co-production/ (accessed 16 November 2020).

23. NIHR INVOLVE https://www.invo.org.uk/wp-content/uploads/2019/02/Being-Inclusive-HealthResearch.pdf (accessed 16 November 2020)

24. NIHR INVOLVE: A Practical Guide to Being Inclusive in Public Involvement in Health Research lessons from the Reaching Out Programme https://www.invo.org.uk/wpcontent/uploads/2020/03/INVOLVE_RO_report_FINAL_180220.pdf (accessed 16 November 2020).

25. Improving inclusion of under-served groups in clinical research: Guidance from INCLUDE project https://www.nihr.ac.uk/documents/improving-inclusion-of-under-served-groups-in-clinical-researchguidance-from-include-project/25435 (accessed 16 November 2020).

26. Young Foundation. Defining Social Innovation 2012 https://youngfoundation.org/wpcontent/uploads/2012/12/TEPSIE.D1.1.Report.DefiningSociallnnovation.Part-1-defining-socialinnovation.pdf (accessed 16 November 2020).

27. Starling B, Tanswell J. Diversifying audiences and producers of public involvement in scientific research. Research Involvement and Engagement 2018; 4:39 https://doi.org/10.1186/s40900-0180122

28. https://www.wearevocal.org/ (accessed 16 November 2020).

29. GM BME Network https://www.gmcvo.org.uk/greater-manchester-bme-network (accessed 16 November 2020).

30. Creative Health: the Arts for Health and Wellbeing https://www.culturehealthandwellbeing.org.uk/appg-inquiry/ (accessed 16 November 2020).

31. Using art to engage with people often not involved in research development and production https://www.spcr.nihr.ac.uk/news/blog/using-art-to-engage-with-people (accessed 16 November 2020).

32. https://www.manchesterbrc.nihr.ac.uk/how-we-do-it/addressing-health-inequalities/ (accessed 16 November 2020).

33. http://blog.policy.manchester.ac.uk/posts/2020/04/how-inequalities-are-affecting-the-response-tocovid-19/ (accessed 16 November 2020)

\section{Figures}




\title{
NHS
}

Manchester Biomedical Research Centre Manchester Clinical Research Facility

\section{Community Voices in Health Research across}

\section{Greater Manchester}

\section{A fun and engaging event learning}

how community voices can shape and influence health research

An opportunity to collaborate with researchers/community artists and pitch for some funding (up to $\mathrm{E750 \text {) }}$ to host your own event

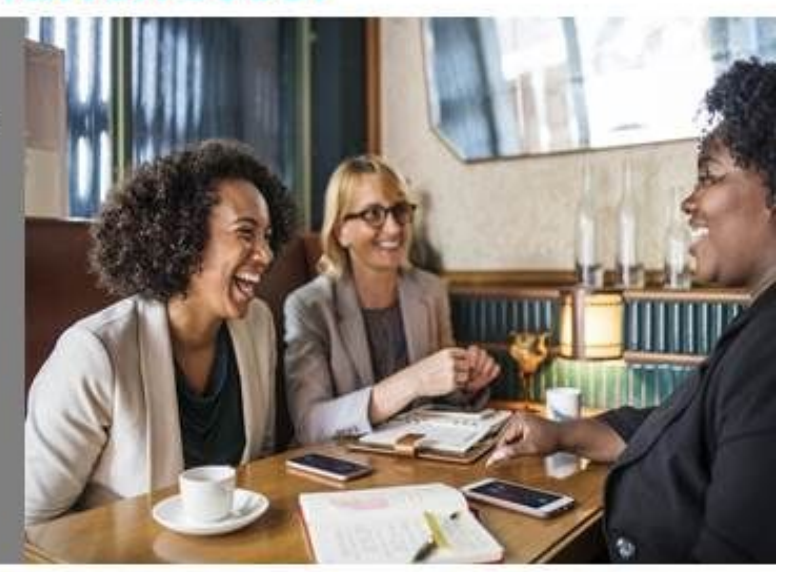

Come and join us to experience a new way of getting some seed funding for the Community Sandpit in Health Research Event

\author{
on $17^{\text {th }}$ and $19^{\text {th }}$ July \\ in Manchester City Centre
}

Community Engagement Fee ( $£ 150$ ] available for each day Travel expenses within Greater Manchester paid Lunch and Refreshments provided

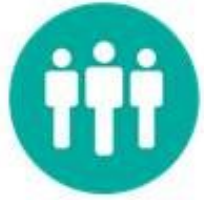

Figure 1

In July 2018, a two day community sandpit event brought together over 30 Voluntary and Community Sector (VCS) organisation representatives, creative practitioners, community leaders, researchers and public involvement practitioners from across Greater Manchester (GM, Figure 1, event flyer). 


\section{WHS}

Manchester Biomedical Research Centre

Manchester Clinical Research Facility

National Institute for

Health Research

\section{Community Voices in Health Research across}

\section{Greater Manchester}

\section{A fun and engaging event learning}

how community voices can shape and

influence health research

An opportunity to collaborate with researchers/community artists and pitch for some funding (up to f750) to host your own event

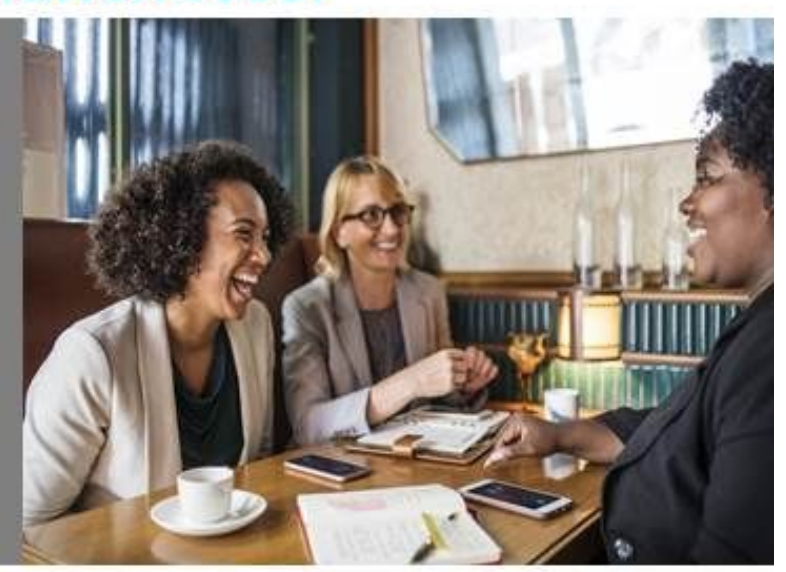

Come and join us to experience a new way of getting some seed funding for the Community Sandpit in Health Research Event

$$
\begin{aligned}
& \text { on } 17^{\text {th }} \text { and } 19^{\text {th }} \text { July } \\
& \text { in Manchester City Centre }
\end{aligned}
$$

Community Engagement Fee ( $\{150$ ] available for each day Travel expenses within Greater Manchester paid Lunch and Refreshments provided

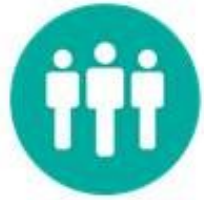

Figure 1

In July 2018, a two day community sandpit event brought together over 30 Voluntary and Community Sector (VCS) organisation representatives, creative practitioners, community leaders, researchers and public involvement practitioners from across Greater Manchester (GM, Figure 1, event flyer). 